\title{
W. L. Mang, Mein Schönheitsbuch (My Beauty Book)-In German
}

\author{
Trias, Stuttgart, 2008, 224 pages, ISBN: 3-8304-3133-3, \$46.00 USD
}

\section{Leo Clodius}

Received: 1 April 2010 /Accepted: 1 April 2010 /Published online: 8 June 2010

(C) Springer-Verlag 2010

In the foreword, the author claims to be the pioneer of "beauty surgery" in Germany and draws attention to the nonreversible trend of the general attitude to the rapid increase in this kind of lifestyle surgery. Good looks and fitness, according to the author, seem to guarantee rapid success. This is the principal motivation for the author's suggestions.

This book was mainly written to provide information for patients interested in undergoing cosmetic surgery and to be treated at the clinic of the author. The contents provide both advice for useful conservative health strategies (e.g., antiaging, well-being, nutrition) and for understanding the possibilities and risks of the various cosmetic surgical interventions.

Whoever can master the German language and is interested in improving his or her personal appearance will find some very useful information in this book. 